\title{
VERTOVEC (Steven), ROGERS (Alisdair), eds., Muslim European Youth. Reproducing Ethnicity, Religion, Culture
}

Aldershot, Ashgate, 1998, 215 p (coll. « Research in Ethnic Relation Series », Dansk Center for Migration og Etniske Studier)

\section{Giovanni Semi}

\section{(2) OpenEdition}

\section{Édition électronique}

URL : http://journals.openedition.org/assr/20484

DOI : $10.4000 /$ assr.20484

ISSN : $1777-5825$

\section{Éditeur}

Éditions de l'EHESS

Édition imprimée

Date de publication : 31 décembre 2000

Pagination : 173-174

ISBN : 2-222-96698-1

ISSN : 0335-5985

\section{Référence électronique}

Giovanni Semi, «VERTOVEC (Steven), ROGERS (Alisdair), eds., Muslim European Youth. Reproducing Ethnicity, Religion, Culture », Archives de sciences sociales des religions [En ligne], 112 I octobre-décembre 2000, document 112.110, mis en ligne le 19 août 2009, consulté le 21 septembre 2020. URL : http:// journals.openedition.org/assr/20484; DOI : https://doi.org/10.4000/assr.20484

Ce document a été généré automatiquement le 21 septembre 2020.

(C) Archives de sciences sociales des religions 
VERTOVEC (Steven), ROGERS (Alisdair), eds., Muslim European Youth. Reproducing Ethnicity, Religion, Culture

\author{
Aldershot, Ashgate, 1998, 215 p (coll. « Research in Ethnic Relation \\ Series », Dansk Center for Migration og Etniske Studier)
}

\title{
Giovanni Semi
}

\section{RÉFÉRENCE}

VERTOVEC (Steven), ROGERS (Alisdair), eds., Muslim European Youth. Reproducing Ethnicity, Religion, Culture, Aldershot, Ashgate, 1998, 215 p (coll. « Research in Ethnic Relation Series », Dansk Center for Migration og Etniske Studier)

1 Avec cette œuvre collective, les auteurs apportent une utile contribution à la connaissance de la présence islamique (d'origine étrangère, puisqu'on ne parle pas des convertis) en Europe. Comme l'annonce le titre, les différentes contributions cherchent aussi à rendre compte d'une réalité particulière, celle des jeunes.

Le point commun sociologique de toutes ces réflexions est le jugement sur la condition de double-appartenance de ces jeunes ou, si l'on préfère, sur l'hybridation culturelle qu'ils partagent. Vivant dans différents milieux nationaux européens, mais souvent issus de parents nés à l'étranger, ils expérimentent un terrain complexe d'identification et de répulsion (en rapport à la culture "occidentale ", qui leur est proposée par le système éducatif, mais aussi en rapport avec le système symbolique et culturel partagé avec les parents).

3 Les AA. dégagent différentes formes de relation et de comportement. La plus importante à signaler semble être l'adhésion problématique à la religion islamique. Prenons par exemple l'affaire Rushdie :ce qui apparaissait (selon la presse, notamment) 
comme une véritable guerre de religion entre une sorte de primordial irrationalisme islamique et la défense occidentale de la valeur de liberté d'expression, devient, dans l'essai de S.V., une réponse " aux diffus sentiments qu'une insulte avait été portée à leur identité collective ». Comme le signale l'A., à l'époque, des jeunes participaient aux manifestations de protestation sans bien savoir pourquoi, simplement parce qu'ils pressentaient la nécessité d'adhésion.

4 La participation politique n'est pas la seule réaction possible. Il y a également ceux qui préfèrent la fuite. C'est ce que décrit Lenie Brouwer, à propos de jeunes filles turques et marocaines qui préfèrent quitter la maison et fuir le contrôle familial (paternel, mais pas seulement) exercé sur leur propre individualité et sexualité. L'importance placée sur la virginité des filles, perçue comme un banc d'essai pour l'honneur familial, est un des enjeux les plus forts. Les parents en exaspèrent la valeur, craignant la rupture de l'unité familiale dans un contexte étranger comme celui du pays d'immigration (la Hollande dans le cas présent). Ce type de valorisation rend souhaitables les mariages arrangés.

5 Un autre aspect relevé par plusieurs auteurs est la croissante adhésion à l'islam, conçue non pas comme un moyen de fuir le contexte européen, mais plutôt comme sanctionnant la définitive acceptation des responsabilités liées au futur européen de ces jeunes euromusulmans. Ainsi y a-t-il une volonté de ne pas succomber aux (présumées, mais souvent réelles) demandes d'assimilation forcée, c'est-à-dire de ne pas perdre sa propre identité.

6 "Se faire appeler en France comme arabes ou musulmans ne signifie pas communiquer un regret nostalgique mais il est plutôt lié à leur situation en France. Finalement, c'est une réaction à la discrimination » (p. 29) écrit à ce propos Jocelyne Césari.

7 La clarté des points de vue et la générale impression d'un ensemble très riche de résultats achevés dans la recherche empirique sur ce thème, rend ce livre précieux pour les spécialistes de la présence islamique en Europe. Grâce à lui, ce thème peut désormais compter sur une production scientifique vaste et significative. 